NASA Technical Memorandum 104346

\title{
Integrated Mechanics for the Passive Damping of Polymer-Matrix Composites and Composite Structures
}

D.A. Saravanos

Case Western Reserve University

Cleveland, Ohio

and

C.C. Chamis

Lewis Research Center

Cleveland, Ohio

Prepared for the

Mechanics and Mechanisms of Materials Damping Conference sponsored by the American Society for Testing and Materials Baltimore, Maryland, March 13-15, 1991

\section{NRSก}




\title{
INTEGRATED MECHANICS FOR THE PASSIVE DAMPING OF \\ POLYMER-MATRIX COMPOSITES AND COMPOSITE
}

\author{
STRUCTURES \\ D.A. Saravanos* \\ Case Western Reserve University \\ Cleveland, Ohio 44106 \\ and \\ C.C. Chamis \\ National Aeronautics and Space Administration \\ Lewis Research Center \\ Cleveland, Ohio 44135
}

\begin{abstract}
Some recent developments on integrated damping mechanics for unidirectional composites, laminates, and composite structures are reviewed. Simplified damping micromechanics relate the damping of on-axis and off-axis composites to constituent properties, fiber volume ratio, fiber orientation, temperature, and moisture. Laminate and structural damping mechanics for thin composites are summarized. Discrete layer damping mechanics for thick laminates, including the effects of interlaminar shear damping, are developed and semi-analytical predictions of modal damping in thick simply-supported specialty composite plates are presented. Applications demonstrate the advantages of the unified mechanics, and illustrate the effect of fiber volume ratio, fiber orientation, structural geometry, and temperature on the damping. Additional damping predictions for composite plates of various laminations, aspect ratios, fiber content, and temperature illustrate the merits and ranges of applicability of each theory (thin or thick laminates).
\end{abstract}

*NASA Resident Research Associate at Lewis Research Center. 


\section{INTRODUCTION}

The significance of passive damping to the dynamic performance of structures is widely recognized. Damping is a significant dynamic parameter for vibration and sound control, fatigue endurance, and impact resistance. Current light-weight and high-performance requirements imposed on most structural applications restrict the use of many traditional non-structural damping sources. Polymer-matrix composites are known to exhibit significantly higher material damping than most common metals, as a result of the polymer matrix and their heterogeneity. Composites are already preferred in many structural applications due to their high specific stiffness and strength, hence, the option of passive structural damping is an added advantage to these materials.

Various damping mechanics theories for unidirectional composites and laminates [114] have been reported. Work on the damping of composite beams and plates [15-16], and plate/shell composite structures of general geometry and lamination has been also reported [17]. The research has demonstrated that composite damping depends on an array of micromechanical and laminate parameters, temperature, moisture, and existing damage. The composite damping is also anisotropic, but exhibits an opposite anisotropy trend than stiffness and strength, being minimum in the direction of the fibers and maximum in the transverse and shear directions. In addition, the structural composite damping was found to be strongly dependent on structural configuration and deformation state. It is apparent, therefore, that in order to realize significant structural benefits from the damping of composite materials, integrated damping mechanics are required, correlating the damping of composite structures to parameters of the basic constituent materials, laminate configuration, hygro-thermal conditions, and structural geometry. This paper reviews the past and present research at the Lewis Research Center in the development of integrated damping theories for thin and/or thick composites and composite structures. The damping mechanics complement previous work performed at Lewis on integrated composite mechanics [18].

These integrated methodologies enable the synthesis of global damping capacity at the 
structural level, or any intermediate material level, while including the effects from critical parameters at each individual material level (micromechanical, laminate, and structural), friction from broken/debonded fibers, interlaminar layers, temperature, moisture, and global structural geometry and boundary conditions.

Damping micromechanics explicitly relate the on-axis and off-axis damping capacities of the unidirectional composite with the micromechanical parameters and the fiber orientation angle. Two different laminate/structural damping theories have been developed. The first was based on the classical laminate plate theory (CLPT) Kirchoff-Love's assumptions which assume a linear displacement field through the thickness and neglect interlaminar shear effects. The CLPT damping theory combines simplicity, computational speed, and has yielded excellent results for thin laminates and laminated structures subjected predominantly to extensional and/or flexural deformations. An important element of the CLPT laminate damping theory is the inclusion of the interlaminar matrix layer damping, which proved to be a potentially important source of damping for angle-ply laminates. A finiteelement based methodology for the synthesis of the passive damping and the simulation of the damped dynamic response of thin composite structures has also been developed.

Recently, a novel discrete laminate damping theory for the damping of thick composites is developed. The method assumes a piecewise continuous displacement field with variable degrees of freedom through the laminate thickness. The effects of interlaminar shear damping are also included. The discrete damping theory, although computationally more cumbersome, is particularly suitable for thick composite laminates, or laminates where the representation of local interlaminar shear effects are important. A semi- analytical methodology for the prediction of the dynamic properties of simply- supported (SS) specialty thick composite plates based on the aforementioned theory is presented, and results for the modal damping values are reported. Comparisons with structural damping predictions based on the CLPT damping theory illustrate the advantages of both laminate theories.

Application studies and experimental correlations illustrate the merits and the accu- 
racy of these unified damping theories. In addition, they provide valuable information and guidelines for the design of composite laminates/structures with good dynamic characteristics, as well as, for the successful measurement of damping in composites.

\section{COMPOSITE DAMPING}

This section briefly reviews the synthesis of damping for on-axis (damping along the material axes) and off-axis composites (unidirectional composites loaded at an angle), including the effects of temperature and moisture on composite damping. Additional details are provided in Ref. [13].

\section{On-Axis Damping}

For a unidirectional composite loaded along the material axes (Fig. 1a), closed-form expressions have been developed for the synthesis of damping based on elastic hysteretic damping assumptions [13]. For orthotropic but transversely isotropic materials, like unidirectional reinforced composites, six damping coefficients will completely characterize the damping of the composite, that is: (1) longitudinal damping $\psi_{l 1}$ (direction 11), (2) transverse in- plane damping $\psi_{l 2}$ (direction 22), (3) transverse through-the- thickness damping $\psi_{l 3}$ (direction 33), (4) in-plane shear damping $\psi_{l 6}$ (direction 12), (5) interlaminar shear damping $\psi_{l 4}$ (direction 23), and (6) interlaminar shear damping $\psi_{l 5}$ (direction 13). These six damping capacities are explicitly related to fiber/matrix moduli and damping values, and the fiber volume ratio (FVR). Typical damping predictions and experimental correlations for Gr/Epoxy unidirectional composites are shown in Fig. 2.

\section{Off-Axis Damping}

For the case of off-axis composites, ie. composites loaded at an angle (Fig. 1b), a transformation provides the equivalent damping capacity of the composite in the structural coordinate system. Ref. [13] presents the damping transformation for in-plane SDCs. The damping transformation is extended herein, based on the same principle of invariance of the dissipated energy, to include out-of-plane shear and transverse damping. In such case, the off-axis composite damping is best described by the following 6 by 6 damping matrix 
$\left[\psi_{c}\right]$

$$
\left[\psi_{c}\right]=[R]^{T}\left[\psi_{l}\right][R]^{-T}
$$

The transformation matrices $[R]^{T}$ and $[R]^{-T}$ are shown in the Appendix and induce the effect of fiber orientation angle, while the diagonal matrix $\left[\psi_{l}\right]$ represents the on-axis damping values

$$
\left[\psi_{l}\right]=\left[\begin{array}{cccccc}
\psi_{l 1} & 0 & 0 & 0 & 0 & 0 \\
0 & \psi_{l 2} & 0 & 0 & 0 & 0 \\
0 & 0 & \psi_{l 3} & 0 & 0 & 0 \\
0 & 0 & 0 & \psi_{l 4} & 0 & 0 \\
0 & 0 & 0 & 0 & \psi_{l 5} & 0 \\
0 & 0 & 0 & 0 & 0 & \psi_{l 6}
\end{array}\right]
$$

The off-axis ply damping matrix is non-diagonal and has the general form.

$$
\left[\psi_{c}\right]=\left[\begin{array}{cccccc}
\psi_{c 11} & \psi_{c 12} & 0 & 0 & 0 & \psi_{c 16} \\
\psi_{c 21} & \psi_{c 22} & 0 & 0 & 0 & \psi_{c 26} \\
0 & 0 & \psi_{c 33} & 0 & 0 & 0 \\
0 & 0 & 0 & \psi_{c 44} & \psi_{c 45} & 0 \\
0 & 0 & 0 & \psi_{c 54} & \psi_{c 55} & 0 \\
\psi_{c 61} & \psi_{c 62} & 0 & 0 & 0 & \psi_{c 66}
\end{array}\right]
$$

The non-diagonal terms 12 indicate coupling between in-plane extensions, the terms 16 and 26 coupling between the in-plane axial and shear stresses, while the terms 45 the coupling between interlaminar shear stresses. Apparently, off-axis loading will affect the overall damping capacity of the composite in two distinct, yet uncommon to isotropic materials, ways: (1) by altering the values of the diagonal terms, which is equivalent to altering the dissipative capability of the ply directly associated to normal and shear strains, and (2) by inducing and altering non-diagonal terms, which control the amount of strain energy dissipated by coupled deformation modes. This is best illustrated in Fig. 3 where the equivalent axial damping, and the values of the damping terms $\psi_{c 11}, \psi_{c 22}$, and $\psi_{c 66}$ of a $0.50 \mathrm{FVR}$ Gr/Epoxy composite vs. the fiber orientation are plotted. The important effects of fiber orientation and coupling are apparent. 


\section{Hygrothermal Effect}

Many mechanical properties of polymers, including damping, are sensitive to hygrothermal variations. In this manner, temperature and moisture may have a definite effect on the response of polymer composites. Previous studies $[18,19]$ have shown that the hygro-thermal effect on most mechanical properties of the matrix can be modelled as,

$$
\frac{P_{M}}{P_{o}}=\left[\frac{T_{g w}-T}{T_{g d}-T_{o}}\right]^{0.5}
$$

where: $P$ and $T$ represent matrix properties and temperature; subscript $M$ represents Mechanical Properties; and subscripts $o, g d, g w$ respectively indicate room, dry glass transition and glass transition conditions. An inverted form of eq. (4) has been proposed for the hygro-thermal effect on the matrix damping:

$$
\frac{P_{d}}{P_{o}}=\left[\frac{T_{g d}-T_{o}}{T_{g w}-T}\right]^{q}
$$

The wet glass transition temperature is [19],

$$
T_{g w}=T_{g d}\left(0.005 m_{l}^{2}-0.1 m_{l}+1\right)
$$

where $m_{l}$ is the moisture content. The exponent $q$ in eq. (5) can be correlated to experimental damping data of each individual polymer matrix. In the present paper an average value $\mathrm{q}=0.5$ is assumed. The effects of temperature and moisture on the composite damping are introduced based on the previously described micromechanics. A similar approach is used for other mechanical properties.

\section{LAMINATE DAMPING}

Two different laminate damping mechanics theories have been developed for thin and thick laminates, respectively. The first is based on the CLPT Kirchoff-Love assumptions and has provided excellent correlations with experimental results. The second is based on discrete layer laminate plate theory (DLPT) and incorporates a piecewise continuous deflection field of variable degrees of freedom. The discrete layer damping theory (DLDT) is developed to model the damping of thick laminates, or laminates where the interlaminar 
shear effects are non-negligible. The assumed displacement fields for both laminate theories are shown in Fig. 4. In both cases, the dissipated strain energy in the laminate is defined as,

$$
\Delta w_{L}=1 / 2 \int_{-h / 2}^{h / 2} \epsilon_{\mathrm{c}}{ }^{T}\left[E_{c}\right]\left[\psi_{c}\right] \epsilon_{\mathrm{c}} d z
$$

and the maximum laminate strain energy

$$
w_{L}=1 / 2 \int_{-h / 2}^{h / 2} \epsilon_{\mathrm{c}}^{T}\left[E_{c}\right] \epsilon_{\mathrm{c}} d z
$$

where $\left[E_{c}\right]$ is the off-axis stiffness matrix (see Appendix). The equivalent laminate specific damping capacity (SDC) then is,

$$
\psi_{L}=\Delta w_{L} / w_{L}
$$

\section{Thin Laminates}

An overview of the laminate damping theory for thin laminates [14] is provided here. Based on the Kirchoff-Love's assumptions of uniform linear displacements through the thickness and no interlaminar shear, the laminate strain $\epsilon_{\mathrm{c}}$ contains only in-plane strains which are related to the mid-plane strain $\epsilon^{\circ}$ and curvature $\mathbf{k}$ as follows:

$$
\epsilon_{c i}=\left\{\epsilon_{i}^{o}, k_{i}\right\}\{1, z\}^{T} \quad(i=1,2,6)
$$

Combination of eqs. $(7,10)$ and integration through the thickness provides the dissipated strain energy of the laminate, expressed in terms of the 3 by 3 damping matrices $\left[A_{d}\right],\left[C_{d}\right]$, and $\left[D_{d}\right]$ (see Appendix) which are related to the properties of the composite laminate only.

$$
\Delta w_{L}=\frac{1}{2}\left\{\epsilon^{\circ}, \mathbf{k}\right\}\left[\begin{array}{ll}
{\left[A_{d}\right]} & {\left[C_{d}\right]} \\
{\left[C_{d}\right]} & {\left[D_{d}\right]}
\end{array}\right]\left\{\begin{array}{c}
\epsilon^{\circ} \\
k
\end{array}\right\}
$$

The previous expression is complete, in that, it represents general laminate configurations and deformations. Indeed, the extensional damping matrix $\left[A_{d}\right]$ represents the laminate damping capacity in pure extension, the flexural damping matrix $\left[D_{d}\right]$ represent the laminate damping in pure bending and torsion, and the coupling damping matrix $\left[C_{d}\right]$ is 
associated with coupled extension-flexure deformations. All three matrices in eq. (11) are fully populated. They also include the interlaminar damping contributions of the interply . matrix layer, which have shown to be a significant additional source of damping in composite laminates [14]. Similarly, the maximum laminate strain energy in eq. (8) is expressed as:

$$
w_{L}=\frac{1}{2}\left\{\epsilon^{\circ}, \mathbf{k}\right\}\left[\begin{array}{ll}
{[A]} & {[C]} \\
{[C]} & {[D]}
\end{array}\right]\left\{\begin{array}{c}
\epsilon_{k}^{\mathbf{o}} \\
k
\end{array}\right\}
$$

where $[A],[C]$, and $[D]$ are the extensional, coupling, and flexural laminate stiffness matrices. Therefore, the equivalent damping capacity of a general laminate is calculated by combining eqs. $(9,11,12)$ and is a function of the composite laminate parameters and the specific deformation state $\left\{\epsilon^{\mathrm{o}}, \mathrm{k}\right\}$.

This laminate damping theory has yielded excellent correlations with experimental results. Typical damping predictions for a $0.50 \mathrm{FVR}$ graphite/epoxy $(0+\theta / 90+\theta / 45+$ $\theta /-45+\theta)_{s}$ laminate under cyclic free-flexure (a bending moment $\mathbf{M}=\left(M_{x}, 0,0\right)$ ) is shown in Fig. 5. Additional laminate damping predictions and correlations for various laminate configurations are shown in ref. [14].

\section{Thick Laminates}

A new discrete-layer laminate damping theory (DLDT) is recently developed for thick laminates and/or laminates with significant interlaminar shear effects. In contrast to the CLPT, the present theory assumes a general piecewise continuous in-plane displacement field through the laminate thickness, in addition to the midplane deflections. Discrete layer theories were historically proposed by Grigolyuk [20] and subsequently generalized (see review [21]) for the more accurate calculation of stresses in thick laminates. The authors, however, have realized that they combine the potential for accurate damping predictions in thick laminates, or laminates with weak interlaminar damping layers, where deviations from the CLPT assumptions are expected. The assumed displacement field has the form,

$$
\begin{aligned}
& u(x, y, z, t)=u^{o}(x, y, t)+\bar{u}(x, y, z, t) \\
& v(x, y, z, t)=v^{\circ}(x, y, t)+\bar{v}(x, y, z, t)
\end{aligned}
$$




$$
w(x, y, z, t)=w^{o}(x, y, t)
$$

where superscript $o$ represents the uniform through-the-thickness midplane deflection. Applying a piecewise continuous linear displacement field, as suggested by Reddy and coworkers [22-23], the previous eqs. take the form:

$$
\begin{gathered}
u(x, y, z, t)=u^{o}(x, y, t)+\sum_{j=1}^{N} u^{j}(x, y, t) F^{j}(z) \\
v(x, y, z, t)=v^{o}(x, y, t)+\sum_{j=1}^{N} v^{j}(x, y, t) F^{j}(z) \\
w(x, y, z, t)=w^{o}(x, y, t)
\end{gathered}
$$

where, $u^{j}$ and $v^{j}$ are displacements, along the $\mathrm{x}$ and $\mathrm{y}$ directions respectively, preferably at the interfaces between various plies, or sublaminates (group of plies), and $F^{j}(z)$ are linear interpolation functions. In this manner, the assumed in-plane displacement field is general, in that it may represent general displacement fields and interlaminar shear strains through-the-laminate thickness in the laminate plane.

The laminate strains are directly derived from eqs. (14)

$$
\begin{array}{cc}
\epsilon_{c i}=\epsilon_{c i}^{o}+\sum_{j=1}^{N} \epsilon_{c i}^{j} F^{j}(z) & i=1,2,6 \\
\epsilon_{c i}=\epsilon_{c i}^{o}+\sum_{j=1}^{N} \epsilon_{c i}^{j} F_{, z}^{j}(z) & i=4,5
\end{array}
$$

where, the midplane strains are,

$$
\begin{gathered}
\epsilon_{c 1}^{o}=u_{, x}^{o} \quad \epsilon_{c 2}^{o}=v_{, y}^{o} \quad \epsilon_{c 6}^{o}=u_{, y}^{o}+v_{, x}^{o} \\
\epsilon_{c 4}^{o}=w_{, y}^{o} \quad \epsilon_{c 5}^{o}=w_{, x}^{o}
\end{gathered}
$$

and the generalized strains are,

$$
\epsilon_{c 1}^{j}=u_{, x}^{j} \quad \epsilon_{c 2}^{j}=v_{, y}^{j} \quad \epsilon_{c 6}^{j}=u_{, y}^{j}+v_{, x}^{j}
$$




$$
\epsilon_{c 4}^{j}=v^{j} \quad \epsilon_{c 5}^{j}=u^{j}
$$

The comma in the subscripts indicates differentiation. Combination of eqs. (7, 15-17) ultimately provides the dissipated strain energy per unit area,

$$
\Delta w_{L}=1 / 2\left(\epsilon_{c}^{o T}\left[A_{d}\right] \epsilon_{c}^{o}+2 \epsilon_{c}^{o T} \sum_{j=1}^{N}\left[B_{d}^{j}\right] \epsilon_{c}^{j}+\sum_{j=1}^{N} \sum_{m=1}^{N} \epsilon_{c}^{j T}\left[D_{d}^{j m}\right] \epsilon_{c}^{m}\right)
$$

where, $\left[A_{d}\right]$ is the previously defined extensional laminate damping matrix, but with additional out-of-plane shear terms. The generalized coupling damping matrices $\left[B_{d}^{j}\right]$ and flexural/shear matrices $\left[D_{d}^{j m}\right]$ are new.

$$
\begin{gathered}
{\left[A_{d}\right]=\sum_{k=1}^{N_{l}} \int_{h_{k-1}}^{h_{k}}\left[E_{c}\right]_{k}\left[\psi_{c}\right]_{k} d z} \\
\left(B_{d}^{j}\right)_{i n}=\sum_{k=1}^{N_{l}} \int_{h_{k-1}}^{h_{k}}\left(\left[E_{c}\right]_{k}\left[\psi_{c}\right]_{k}\right)_{i n} F^{j}(z) d z \quad i, n=1,2,6 \\
\left(B_{d}^{j}\right)_{i n}=\sum_{k=1}^{N_{l}} \int_{h_{k-1}}^{h_{k}}\left(\left[E_{c}\right]_{k}\left[\psi_{c}\right]_{k}\right)_{i n} F_{, z}^{j}(z) d z \quad i, n=4,5 \\
\left(D_{d}^{j m}\right)_{i n}=\sum_{k=1}^{N_{l}} \int_{h_{k-1}}^{h_{k}}\left(\left[E_{c}\right]_{k}\left[\psi_{c}\right]_{k}\right)_{i n} F^{j}(z) F^{m}(z) d z \quad i, n=1,2,6 \\
\left(D_{d}^{j m}\right)_{i n}=\sum_{k=1}^{N_{l}} \int_{h_{k-1}}^{h_{k}}\left(\left[E_{c}\right]_{k}\left[\psi_{c}\right]_{k}\right)_{i n} F_{, z}^{j}(z) F_{, z}^{m}(z) d z \quad i, n=4,5
\end{gathered}
$$

In a similar manner, the combination of eqs. $(8,15-17)$ provides the maximum strain energy per unit area,

$$
w_{L}=1 / 2\left(\epsilon_{c}^{o T}[A] \epsilon_{c}^{o}+2 \epsilon_{c}^{o T} \sum_{j=1}^{N}\left[B^{j}\right] \epsilon_{c}^{j}+\sum_{j=1}^{N} \sum_{m=1}^{N} \epsilon_{c}^{j T}\left[D^{j m}\right] \epsilon_{c}^{m}\right)
$$

where, $[A]$ is the previously defined extension laminate damping matrix, however, with additional out-of-plane shear terms. The generalized coupling damping matrices $\left[B^{j}\right]$ and flexural/shear matrices $\left[D^{j m}\right]$ are new.

$$
[A]=\sum_{k=1}^{N_{l}} \int_{h_{k-1}}^{h_{k}}\left[E_{c}\right]_{k} d z
$$




$$
\begin{gathered}
\left(B^{j}\right)_{i n}=\sum_{k=1}^{N_{l}} \int_{h_{k-1}}^{h_{k}}\left(\left[E_{c}\right]_{k}\right)_{i n} F^{j}(z) d z \quad i, n=1,2,6 \\
\left(B^{j}\right)_{i n}=\sum_{k=1}^{N_{l}} \int_{h_{k-1}}^{h_{k}}\left(\left[E_{c}\right]_{k}\right)_{i n} F_{, z}^{j}(z) d z \quad i, n=4,5 \\
\left(D^{j m}\right)_{i n}=\sum_{k=1}^{N_{l}} \int_{h_{k-1}}^{h_{k}}\left(\left[E_{c}\right]_{k}\right)_{i n} F^{j}(z) F^{m}(z) d z \quad i, n=1,2,6 \\
\left(D^{j m}\right)_{i n}=\sum_{k=1}^{N_{l}} \int_{h_{k-1}}^{h_{k}}\left(\left[E_{c}\right]_{k}\right)_{i n} F_{, z}^{j}(z) F_{, z}^{m}(z) d z \quad i, n=4,5
\end{gathered}
$$

The equivalent laminate damping for a given local displacement field is provided by eq. (9).

\section{STRUCTURAL DAMPING}

The present section describes the procedure followed for characterizing the global damping capacity of composite structures. It is clear from the previous sections, that the damping capacity of the composite structure will strongly depend on the global deformation state. This difficulty is overcome by considering the modal damping values, that is, the damping of the structure vibrating solely at the respective modal shapes. Since the vibration modes form a complete set representing the elasto-dynamic response of the structure undergoing small deflections, the modal SDCs provide a complete characterization of the global structural damping. The modal damping coefficients, in connection with other modal parameters, can also provide the damped dynamic response of the structure [24].

Thus, the objective of this section is to present the method for synthesizing modal damping. The modal SDC associated with the $\mathrm{n}$-th vibration mode $\psi_{n}$ is:

$$
\psi_{n}=\frac{\int_{V} \Delta w_{n} d V}{\int_{V} w_{n} d V}
$$

where $\Delta w_{n}$ and $w_{n}$ represent the dissipated and maximum specific modal strain energies per cycle respectively. For the case of laminated composite structures the structural modal damping becomes,

$$
\psi_{n}=\frac{\int_{A} \Delta w_{L n} d A}{\int_{A} w_{L n} d A}
$$


where $\Delta w_{L n}$ and $w_{L n}$ are respectively the dissipated and maximum laminate modal strain energies of the $\mathrm{n}$-th mode.

\section{Thin Composite Structures}

For thin composite structures, eq. (23) is combined with eqs. (11-12) to yield the modal damping. For specialty laminates and simple structural configurations, such as plates and shells, exact mode shapes may be found, and explicit integration of eq. (23) is possible, resulting in analytical expressions for modal damping. Such expressions have been derived by the authors for simply-supported rectangular plates.

More general laminate/structural configurations, however, require a form of approximate solution. As a result, approximate procedures based on finite element discretization were developed [17]. The integrations in eq. (23) are performed numerically, first over the area of the element, and then over the structural area. A specialty finite element was developed with 6 degrees of freedom per node. The damping capacity of the element was represented by the element damping matrix and included membrane, flexural, and coupling damping terms. The complete inclusion of extensional, flexural and coupling terms into the damping element matrix, readily provided the capacity for predicting the damping in composite structures with general laminate configurations and/or material and geometric coupling (for example, thin composite shells, thin- wall box or tubular beams, and so forth). Typical predicted SDCs for three graphite/epoxy composite structures of varying structural complexity, a cantilever beam, plate and shell respectively, are shown in Fig. 6. The assumed lamination was $( \pm \theta)_{5 s}$. Among other issues, Fig. 6 dramatically illustrates the effect of fiber orientation, structural aspect ratio, curvature, and mode order on the structural modal SDCs.

\section{Thick Composite Plates}

A new semi-analytical method for the calculation of damping in simply- supported thick cross-ply composite plates, in connection with the discrete layer laminate damping theory previously described. Assuming a rectangular $\alpha$ by $\beta$ symmetric composite plate with negligible coupling $\left(A_{16}=A_{26}=0, B_{16}^{j}=B_{26}^{j}=0, D_{16}^{j m}=D_{26}^{j m}=0\right)$, the following Navier 
fundamental solutions form a complete set of mode shapes in the $x-y$ plane:

$$
\begin{aligned}
& u_{m n}^{o}(x, y, t)=U_{m n}^{o} \cos (a x) \sin (b y) e^{i \omega t} \\
& v_{m n}^{o}(x, y, t)=V_{m n}^{o} \sin (a x) \cos (b y) e^{i \omega t} \\
& w_{m n}^{o}(x, y, t)=W_{m n}^{o} \sin (a x) \sin (b y) e^{i \omega t} \\
& u_{m n}^{j}(x, y, t)=U_{m n}^{j} \cos (a x) \sin (b y) e^{i \omega t} \\
& v_{m n}^{j}(x, y, t)=V_{m n}^{j} \sin (a x) \cos (b y) e^{i \omega t}
\end{aligned}
$$

Where, $a=m \pi / \alpha$ and $b=n \pi / \beta$. Combination of eqs. $(16,17,24)$ yields the modal mid-plane and generalized strains as separable functions of $\mathrm{x}, \mathrm{y}$ coordinates, time, and amplitudes.

$$
\left\{\epsilon_{m n}^{o}\right\}=\left[B_{m n}^{o}\right]\left\{U_{m n}^{o}\right\} e^{i \omega t}, \quad\left\{\epsilon_{m n}^{j}\right\}=\left[B_{m n}^{j}\right]\left\{U_{m n}^{j}\right\} e^{i \omega t}
$$

where, the terms in matrices $[B]_{m n}$ are sine/cosine functions of $\mathrm{x}, \mathrm{y}$ coordinates and mode order. The amplitude displacement vectors are $\mathbf{U}^{\circ}=\left\{U^{\circ}, V^{\circ}, W^{\circ}\right\}^{T}$ and $\mathbf{U}^{j}=\left\{U^{j}, V^{j}\right\}^{T}$. The kinetic energy through the thickness of the plate is:

$$
K_{L}=1 / 2 \int_{-h / 2}^{h / 2}\{\dot{u}\}^{T} \rho\{\dot{u}\} d z
$$

Considering eqs. (14) the laminate kinetic energy per unit area takes the form:

$$
K_{L}=1 / 2\left(\left\{\dot{u}^{\circ}\right\}^{T}\left[A_{M}\right]\left\{\dot{u}^{\circ}\right\}+2\left\{\dot{u}^{\circ}\right\}^{T} \sum_{j=1}^{N}\left[B_{M}^{j}\right]\left\{\dot{u}^{j}\right\}+\sum_{j=1}^{N} \sum_{m=1}^{N}\left\{\dot{u}^{j}\right\}^{T}\left[D_{M}^{j m}\right]\left\{\dot{u}^{m}\right\}\right)
$$

where the generalized laminate mass matrices are

$$
\begin{gathered}
{\left[A_{M}\right]=\sum_{k=1}^{N_{l}} \int_{h_{k-1}}^{h_{k}} \operatorname{diag}\left(\rho_{k}\right) d z} \\
{\left[B_{M}^{j}\right]=\sum_{k=1}^{N_{l}} \int_{h_{k-1}}^{h_{k}} \operatorname{diag}\left(\rho_{k}\right) F^{j}(z) d z}
\end{gathered}
$$




$$
\left[D_{M}^{j m}\right]=\sum_{k=1}^{N_{l}} \int_{h_{k-1}}^{h_{k}} \operatorname{diag}\left(\rho_{k}\right) F^{j}(z) F^{m}(z) d z
$$

The term $\operatorname{diag}\left(\rho_{k}\right)$ indicates a diagonal matrix, with all diagonal terms equal to the density of the k-th ply.

By substituting eqs. (25) into the strain and kinetic laminate energy, eqs. (20) and (27), integrating over the plate area, and applying Lagrangian dynamics, it is proved that the undamped modal analysis (free vibration) solution of the plate takes the form:

$$
-\omega_{m n}^{2}\left[M_{m n}\right] \mathbf{U}_{m n}+\left[K_{m n}\right] \mathbf{U}_{m n}=0
$$

where, $\mathbf{U}_{m n}=\left\{\mathbf{U}_{m n}^{\circ} ; \mathbf{U}_{m n}^{1}, \ldots, \mathbf{U}_{m n}^{N}\right\}$. Numerical solution of this eigenvalue problem provides the natural frequencies and the through-the-thickness modes for each order $\mathrm{mn}$ of plane modes, in the context of eqs. (24).

The modal damping of each mode is subsequently calculated, in accordance with eq. (23). First eqs. (19) and (21) are integrated through-the-thickness, and are combined with eqs. (18) and (20) respectively. Then the generalized stresses and strains are related to the calculated mode shape using eq. (25). The integrations over the area of the plate are performed analytically. Only the natural frequencies and the mode shapes through-thethickness are calculated numerically, hence, the whole procedure is semi-analytical.

An analogous procedure was also developed for the exact analytical solution of the natural frequencies and modal SDCs of thin rectangular plates based on the CLPT assumptions. In the remaining paragraphs, predictions with both thick and thin composite damping theories are shown.

Predicted results for the first 10 modes of a square $406 \mathrm{~mm}$ by 406 (16in by $16 \mathrm{in}$ ) simply-supported (SS) plate, $4.06 \mathrm{~mm}$ thick (0.16 in), of $160.50 \mathrm{FVR} \mathrm{Gr} /$ Epoxy plies, each 0.01 in thick, based on both discrete layer plate theory (DLPT) and CLPT are shown in Table 1. Three laminate configurations are investigated: (1) a unidirectional plate $(0)_{16}$, (2) cross-plies $\left(0_{4} / 90_{4}\right)_{s}$, and (3) alternating cross-plies $(0 / 90)_{4 s}$. The fibers in the 0 degs plies are parallel with the $\mathrm{x}$ axis and 16 discrete linear displacement segments, one in each ply, were used $(\mathrm{N}=17)$. As seen, the modal SDCs vary widely with the modal shape. 
In all cases, the differences in the prediction of the first few modal SDCs is small and both theories show good agreement in the prediction of natural frequencies. For this plate of high aspect ratio, this was expected and lends credence to the method. However, the differences between the modal damping of higher order modes of the $0 / 90$ plates, is greater than in the case of the unidirectional plate. This is attributed to the higher interlaminar shear stresses developed in the transverse plies in order to balance the normal stresses in the longitudinal plies.

The fundamental modal SDC and natural frequency of a square $0.50 \mathrm{FVR}\left(0_{4} / 90_{4}\right)_{\mathrm{s}}$ $\mathrm{Gr} /$ Epoxy plate are plotted in Fig. 7 for varying aspect ratios $\alpha / h$. At aspect ratios greater that 50, both CLPT and DLPT give comparable predictions, which again reinforces the validity of the DLPT damping method. At aspect ratios lower that 50 , the DLPT damping method gives significantly higher predictions of damping than the CLPT, because the interlaminar shear effects are important, which illustrates the superiority of the methodology. The differences in frequency predictions are small.

To illustrate the potential of the unified composite damping methodologies presented herein, the fundamental SDC and natural frequency of a $203 \mathrm{~mm}$ by $203 \mathrm{~mm}$ ( 8 in by 8 in), $\left(0_{4} / 90_{4}\right)_{s} \mathrm{Gr} /$ epoxy plate for varying FVR, either in the 90 degs plies only or the 0 degs plies only, are shown in Fig. 8. The modal damping is rather insensitive to the FVR variation in the 90 degs plies, however, the DLPT predicts significantly higher damping at low FVR. It is recalled that at low FVR, the shear modulus $G_{l 23}$ is reduced, hence, higher strain energy is stored in the 90 degs plies to balance the bending stress in the 0 degs plies, moreover, the interlaminar shear damping is increased. The variation of the FVR in the 0 degs plies has a definite effect on the modal damping and frequency, but both theories provide equivalent results.

Predictions of the fundamental SDC and natural frequency of the same plate, subjected to uniform through-the-thickness temperature variations are plotted in Fig. 9. The CLPT significantly underestimates the fundamental SDC at higher temperatures. It is recalled, that in higher temperatures, the shear modulus of the 90 degs plies decreases and 
the shear damping increases respectively. The temperature variation has little effect on the natural frequency.

\section{CONCLUSIONS}

The paper presented an update on past and present research work performed by the authors on the development of unified theories for the damping of polymer composites and composite structures at NASA-Lewis Research Center. Damping mechanics for composites were developed in a unified sense, that is, for all three stages of structural complexity (micromechanical, laminate, and structural), including hygrothermal effects, and effects of interlaminar shear. Laminate and structural damping mechanics for thin composite laminates of general laminate configurations were first developed and reported. The damping mechanics can handle extensional, flexural and coupled deformations, therefore, can predict the damping of symmetric, antisymmetric, and/or fully asymmetric laminates, or the damping of compusite structures with geometric coupling such as thin-wall beams, shells, and so lorth. Representative results and experimental correlations were presented.

Damping mechanics for thick composite laminates/structures are presently under development and a unified discrete-layer damping theory was presented. The discrete displacement field of variable degrees of freedom enabled the calculation of interlaminar shear strains and the incorporation of interlaminar shear damping. Semi-analytical solutions were developed for the prediction of damped dynamic characteristics of thick composite laminates. Comparisons with the CLPT damping theory illustrated that for high aspect ratios both theories give comparable results. However the discrete- layer theory provided better predictions, in specific cross-ply laminate configurations, low aspect ratios, highorder modes, cross-plies with inner plies of low FVR, and cross-plies at higher temperatures. Both theories yielded comparable predictions of natural frequencies in most cases.

Overall, the presented evaluations of the method demonstrated the power and versatility of these integrated composite damping mechanics. The damping mechanics have been incorporated into in-house research codes, including ICAN [18]. Subjects of future research will be composite laminates with interlaminar damping layers, and the effects 
of damping improvements on the stiffness, natural frequencies, buckling resistance, and impact performance of thick composite structures.

\section{REFERENCES}

1. Hashin, Z., "Complex Moduli of Viscoelastic Composites - II. Fiber Reinforced Composite Materials," International Journal of Solids and Structures, Vol. 6, 1970, pp. 797-807.

2. Schultz, A. B., and Tsai, S. W., "Dynamic Moduli and Damping Ratios of Fiber Reinforced Composites," Journal of Composite Materials, Vol. 2, No.3, Jul. 1968, pp. 368-379.

3. Schultz, A. B., and Tsai, S. W., "Measurements of Complex Dynamic Moduli for Laminated Fiber-Reinforced Composites," Journal of Composite Materials, Vol. 3, 1969, pp. 434-443.

4. Adams, R. D., Fox, M. A. O., Flood, R. J. L., Friend R. J., and Hewitt R. L., "The Dynamic Properties of Unidirectional Carbon and Glass Fiber-Reinforced Plastics in Torsion and Flexure," Journal of Composite Materials, Vol. 3, 1969, pp. 594-603.

5. Adams, R. D., and Bacon, D. G. C., "Measurement of the Flexural Damping Capacity and Dynamic Young's Modulus of Metal and Reinforced Plastics," Journal of Physics, D: Applied Physics, Vol. 6, 1973, pp. 27-41.

6. Adams, R. D., and Bacon, D. G. C., "Effect of Fibre Orientation and Laminate Geometry on the Dynamic Properties of CFRP," Journal of Composite Materials, Vol. 7, Oct. 1973, pp. 402-428.

7. Ni, R. G., and Adams, R. D., "A Rational Method for Obtaining the Dynamic Mechanical Properties of Laminae for Predicting the Stiffness and Damping of Laminated Plates and Beams," Composites, Vol. 15, No. 3, July 1984, pp. 193-199.

8. Chang, S., and Bert, C. W., "Analysis of Damping for Filamentary Composite Materials," Composite Materials in Engineering Design, American Society for Metals, Metals Park, 1973, pp. 51-62. 
9. Siu, C. C., and Bert, C. W., "Sinusoidal Response of Composite-Material Plates with Material Damping," ASME Journal of Engineering for Industry, May 1974, pp. 603610 .

10. Gibson, R. F., and Plunkett, R., "Dynamic Mechanical Behavior of Fiber-Reinforced Composites: Measurement and Analysis," Journal of Composite Materials, Vol. 10, Oct. 1976, pp. 325-341.

11. Sun, C. T., Chaturvedi, S. K., and Gibson, R. F., "Internal Damping of Short-Fiber Reinforced Polymer Matrix Composites," Computers and Structures, Vol. 20, No. 1-3, 1985, pp. 391-400.

12. Suarez, S. A., Gibson, R. F., Sun, C. T., and Chaturvedi, S. K., "The Influence of Fiber Length and Fiber Orientation on Damping and Stiffness of Polymer Composite Materials," Experimental Mechanics, Vol. 26, No. 2, 1986, pp. 175-184.

13. Saravanos, D. A. and Chamis, C. C. "Unified Micromechanics of Damping for Unidirectional and Off-Axis Fiber Composites," Journal of Composites Technology and Research, Vol. 12, No. 1, 1990, pp. 31-40.

14. Saravanos, D. A. and Chamis, C. C. "Mechanics of Damping for Fiber Composite Laminates Including Hygro-Thermal Effects," AIAA Journal, Vol. 28, No. 10, 1990, pp. 1813-1819.

15. Ni, R. G., and Adams, R. D., " The Damping and Dynamic Moduli of Symmetric Laminated Composite Beams - Theoretical and Experimental Results," Journal of Composite Materials, Vol. 18, 1984, pp. 104-121.

16. Cawley, P. and Adams, R. D. "The Predicted and Experimental Natural Modes of Free-Free CFRP Plates," Journal of Composite Materials, 12:336-347 (1978).

17. Saravanos, D. A. and Chamis, C. C. "Computational Simulation of Damping in Composite Structures," Journal of Reinforced Plastics and Composites, to appear, 1991, (also, NASA TM-102567, 1990).

18. Murthy, P. L. N., and Chamis, C. C., "ICAN: Integrated Composite Analyzer," AIAA Paper 84-0974, May 1984. 
19. Chamis, C. C., "Simplified Composite Micromechanics Equations for Hygral, Thermal, and Mechanical Properties," SAMPE Quarterly, Vol. 15, No. 3, April 1984, pp. 14-23.

20. Grigolyuk, E. I. and Kogan, F. A., "State-of-the-art of the theory of Multilayer Shells," Engl. translation in Sov. Applied Mechanics, Vol. 8, No. 6, 1974, pp. 583-595.

21. Noor, A. K. and Burton, S. W., "Assessment of Computational Models for Multilayer Composite Shells," Applied Mechanics Reviews, Vol. 43, No. 4, 1990, pp. 67-96.

22. Barbero, E. J., Reddy, J. N. and Teply, J., "An Accurate Determination of Stresses in Thick Composite Laminates Using a Generalized Plate Theory," Int. Journal for Numerical Methods in Engineering, Vol. 29, 1990, pp. 1-14.

23. Reddy, J. N., Barbero, E. J. and Teply, J., "A Plate Bending Element Based on a Generalized Laminate Plate Theory," Int. Journal for Numerical Methods in Engineering, Vol. 28, 1989, pp. 2275-2292.

24. Saravanos, D. A. and Chamis, C. C. "A Computational Methodology for Optimizing the Passive Damping of Composite Structures," Journal of Polymer Composites, Vol. 11, No. 6, 1990, pp. 328-336.

\section{APPENDIX}

Off-axis ply stiffness matrix $\left[E_{c}\right]$ (ref. 18):

$$
\begin{gathered}
\left\{\sigma_{c}\right\}=\left[E_{c}\right]\left\{e_{c}\right\} \\
{\left[E_{c}\right]=[R]^{-1}\left[E_{l}\right][R]^{-T}}
\end{gathered}
$$

Transformation matrices:

$$
\begin{gathered}
{[R]=\left[\begin{array}{cccccc}
m^{2} & n^{2} & 0 & 0 & 0 & 2 m n \\
n^{2} & m^{2} & 0 & 0 & 0 & -2 m n \\
0 & 0 & 1 & 0 & 0 & 0 \\
0 & 0 & 0 & m & n & 0 \\
0 & 0 & 0 & -n & m & 0 \\
-m n & m n & 0 & 0 & 0 & m^{2}-n^{2}
\end{array}\right], \quad m=\cos \theta, \quad n=\sin \theta} \\
{[R]^{-1}=[R(-\theta)]}
\end{gathered}
$$


Laminate damping matrices (CLPT):

$$
\begin{gathered}
{\left[A_{C D}\right]=\sum_{i=1}^{N_{l}} t_{l, i}\left[E_{c}\right]_{i}^{T}\left[\psi_{c}\right]_{i}+\sum_{i=1}^{N_{l}-1} H_{i}[S]_{i}\left[\psi_{m}\right]_{i}} \\
{\left[C_{C D}\right]=\sum_{i=1}^{N_{l}} \frac{1}{2}\left(z_{t}^{2}-z_{b}^{2}\right)_{i}\left[E_{c}\right]_{i}^{T}\left[\psi_{c}\right]_{i}+\sum_{i=1}^{N_{l}-1} z_{r p, i} H_{i}[S]_{i}\left[\psi_{m}\right]_{i}} \\
{\left[D_{C D}\right]=\sum_{i=1}^{N_{l}} \frac{1}{3}\left(z_{t}^{3}-z_{b}^{3}\right)_{i}\left[E_{c}\right]_{i}^{T}\left[\psi_{c}\right]_{i}+\sum_{i=1}^{N_{l}-1} z_{r p, i}^{2} H_{i}[S]_{i}\left[\psi_{m}\right]_{i}}
\end{gathered}
$$

The interply distortion energy coefficient $H$, and matrix $[\mathrm{S}]$ are described in ref. 18. 
Table 1. Modal characteristics of square simply supported plates

\begin{tabular}{|c|c|c|c|c|c|}
\hline \multirow[t]{2}{*}{ Mode } & \multirow[t]{2}{*}{$(\mathbf{n}, \mathbf{m})$} & \multicolumn{2}{|c|}{ Nat. frequency $(\mathrm{Hz})$} & \multicolumn{2}{|c|}{ Modal Damping, \% } \\
\hline & & (DLPT) & (CLPT) & (DLPT) & (CLPT) \\
\hline \multicolumn{6}{|c|}{$\left(0_{16}\right)$ Plate } \\
\hline 1 & $(1,1)$ & 128.8 & 129.2 & 1.035 & 0.996 \\
\hline 2 & $(1,2)$ & 161.5 & 161.9 & 2.561 & 2.531 \\
\hline 3 & $(1,3)$ & 240.2 & 240.8 & 3.861 & 3.842 \\
\hline 4 & $(1,4)$ & 367.3 & 368.5 & 4.399 & 4.389 \\
\hline 5 & $(2,1)$ & 490.8 & 496.8 & 0.761 & 0.606 \\
\hline 6 & $(2,2)$ & 510.6 & 516.8 & 1.148 & 0.996 \\
\hline 7 & $(1,5)$ & 538.8 & 541.2 & 4.582 & 4.575 \\
\hline 8 & $(2,3)$ & 556.3 & 562.8 & 1.827 & 1.684 \\
\hline 9 & $(2,4)$ & 640.7 & 647.8 & 2.654 & 2.531 \\
\hline 10 & $(2,5)$ & 772.3 & 780.4 & 3.390 & 3.294 \\
\hline \multicolumn{6}{|c|}{$\left(0_{4} / 90_{4}\right)$ s Plate } \\
\hline 1 & $(1,1)$ & 128.8 & 129.2 & 1.026 & 0.996 \\
\hline 2 & $(1,2)$ & 231.1 & 231.9 & 1.464 & 1.428 \\
\hline 3 & $(1,3)$ & 449.5 & 452.8 & 1.440 & 1.357 \\
\hline 4 & $(2,1)$ & 461.7 & 468.2 & 0.764 & 0.635 \\
\hline 5 & $(2,2)$ & 510.1 & 516.8 & 1.113 & 0.996 \\
\hline 6 & $(2,3)$ & 652.5 & 660.5 & 1.437 & 1.326 \\
\hline 7 & $(1,4)$ & 767.6 & 777.5 & .. 1.428 & 1.279 \\
\hline 8 & $(2,4)$ & 914.4 & 927.7 & 1.572 & 1.428 \\
\hline 9. & $(3,1)$ & 1011.0 & 1043.0 & 0.845 & 0.562 \\
\hline 10 & $(3,2)$ & 1041.0 & 1074.0 & 1.012 & 0.736 \\
\hline \multicolumn{6}{|c|}{$(0 / 90)_{4 s}$ Plate } \\
\hline 1 & $(1,1)$ & 128.9 & 129.2 & 1.019 & 0.996 \\
\hline 2 & $(1,2)$ & 338.0 & 340.3 & 0.931 & 0.865 \\
\hline 3 & $(2,1)$ & 392.9 & 396.5 & 0.823 & 0.737 \\
\hline 4 & $(2,2)$ & 512.1 & 5.168 & 1.076 & 0.996 \\
\hline 5 & $(1,3)$ & 720.8 & 732.0 & 0.904 & 0.752 \\
\hline 6 & $(2,3)$ & 827.2 & 839.6 & 1.103 & 0.964 \\
\hline 7 & $(3,1)$ & 852.1 & 869.7 & 0.837 & 0.643 \\
\hline 8 & $(3,2)$ & 922.2 & 940.3 & 1.025 & 0.846 \\
\hline 9 & $(3,3)$ & 1140.0 & 1163.0 & 1.173 & 0.996 \\
\hline 10 & $(1,4)$ & 1254.0 & 1288.0 & 0.972 & 0.706 \\
\hline
\end{tabular}




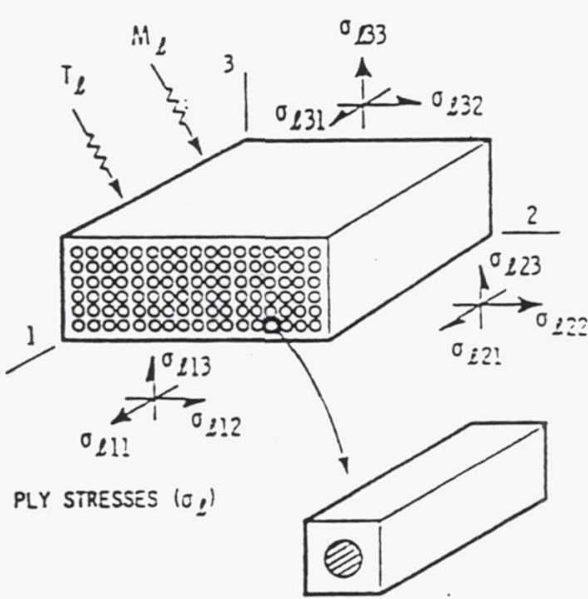

(a) ON-AXIS

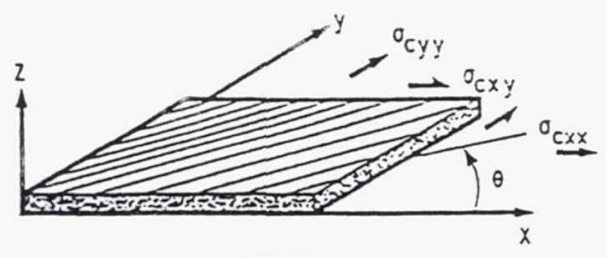

(b) OFF-AXIS

FIGURE : - UNIDIRECTIONAL COMPOSITES.

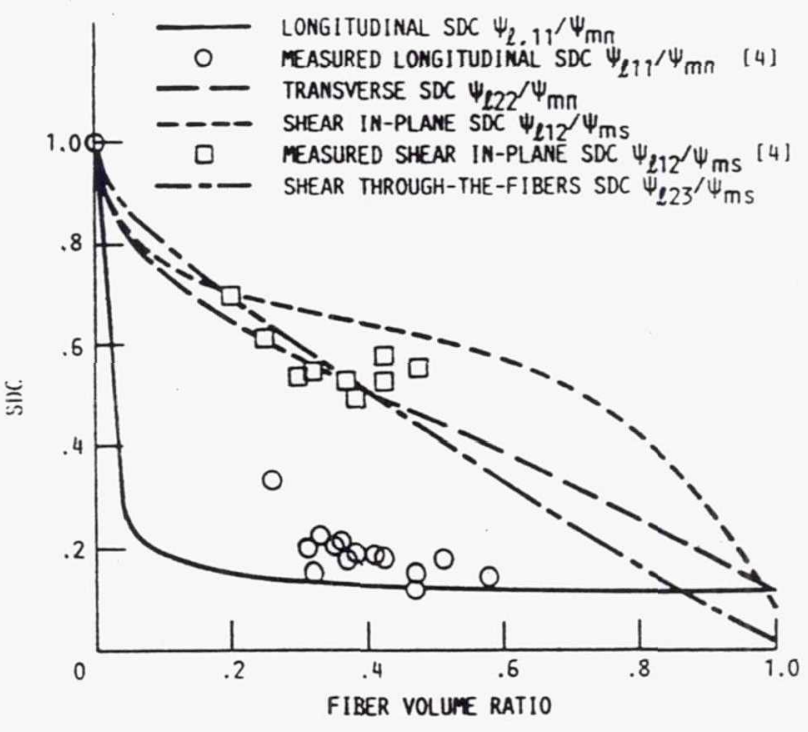

FIGURE 2.-TYPICAL SOC'S FOR HM-S GRAPHITEIPOLYESTER.

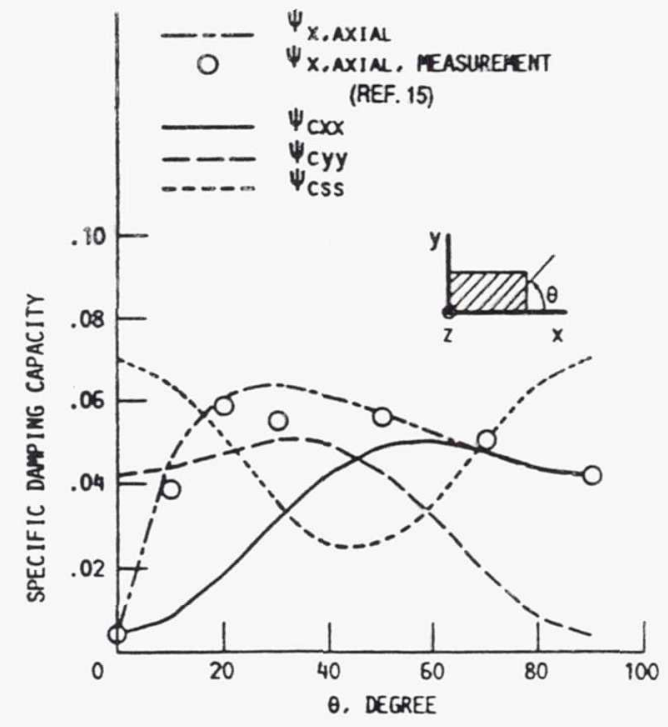

FGURE 3. -EFFECT OF ABER ORIENTATION ON THE DAMPING OF A 0.5O FVR HIMSKEPOXY COMPOSTIES
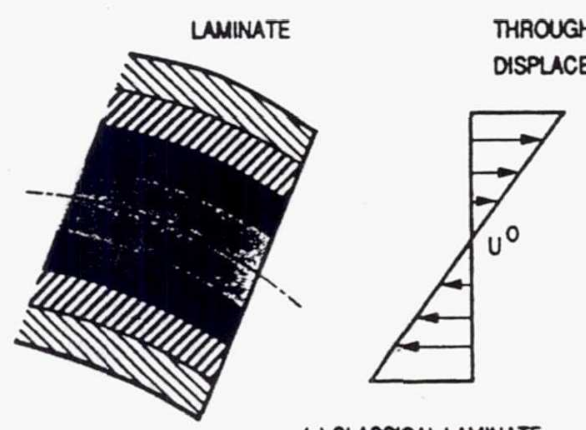

(a) CLASSICAL LUMINATE PLATE THEORY (CLPT) (THIN UNATATES)
HROUGH-THE-THICKNESS ISPLACEMENTS

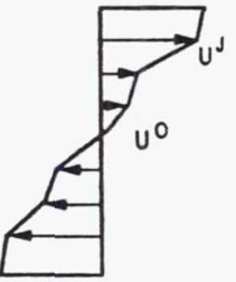

(b) DISCRETE LAMINATE PLATE THEORY (DLPT) (THICK LAMINATES) 


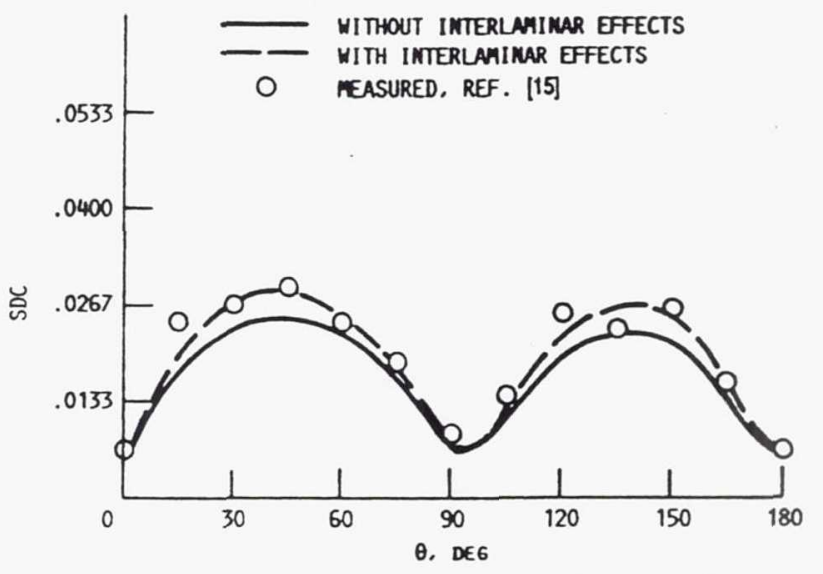

FIGURE 5. - FLEXURAL DAMPING OF A 0.50 FVR HM-SIEPOXY $(\theta / 90+\theta / 45+\theta / 45+\theta)_{S}$ LAMINATE 


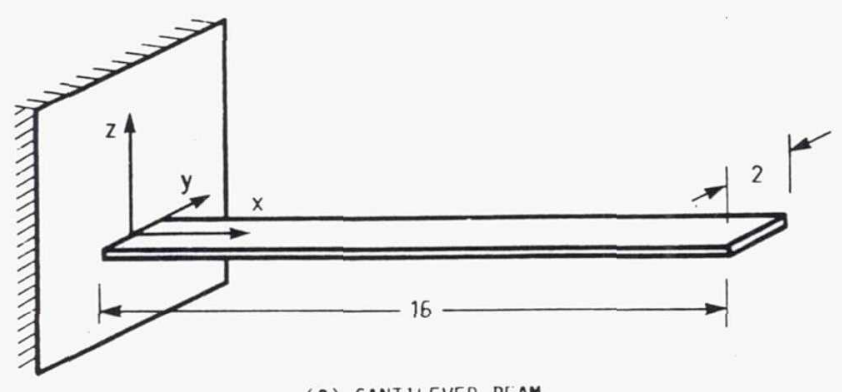

(a) CANTILEVER BEAM.

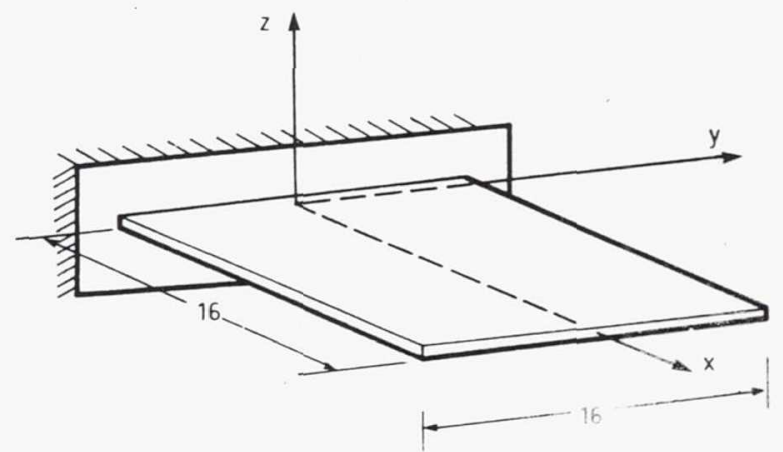

(b) CANTILEVER PLATE.

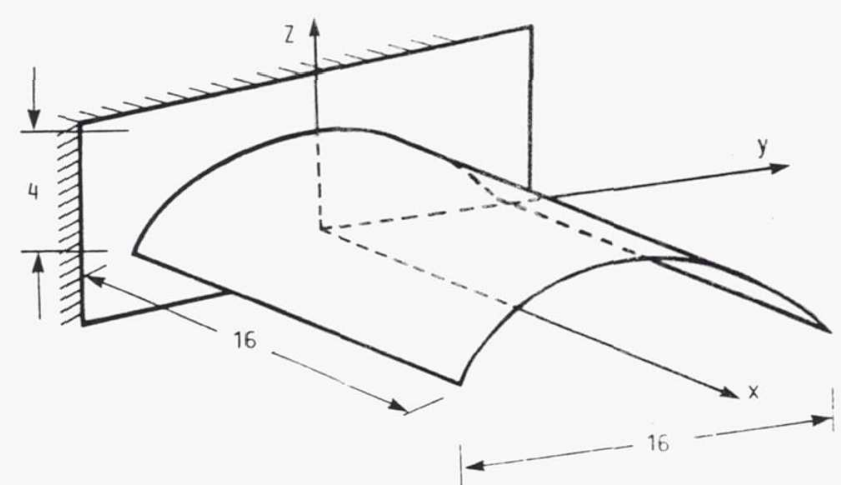

(C) CANTILEVER SHELL.
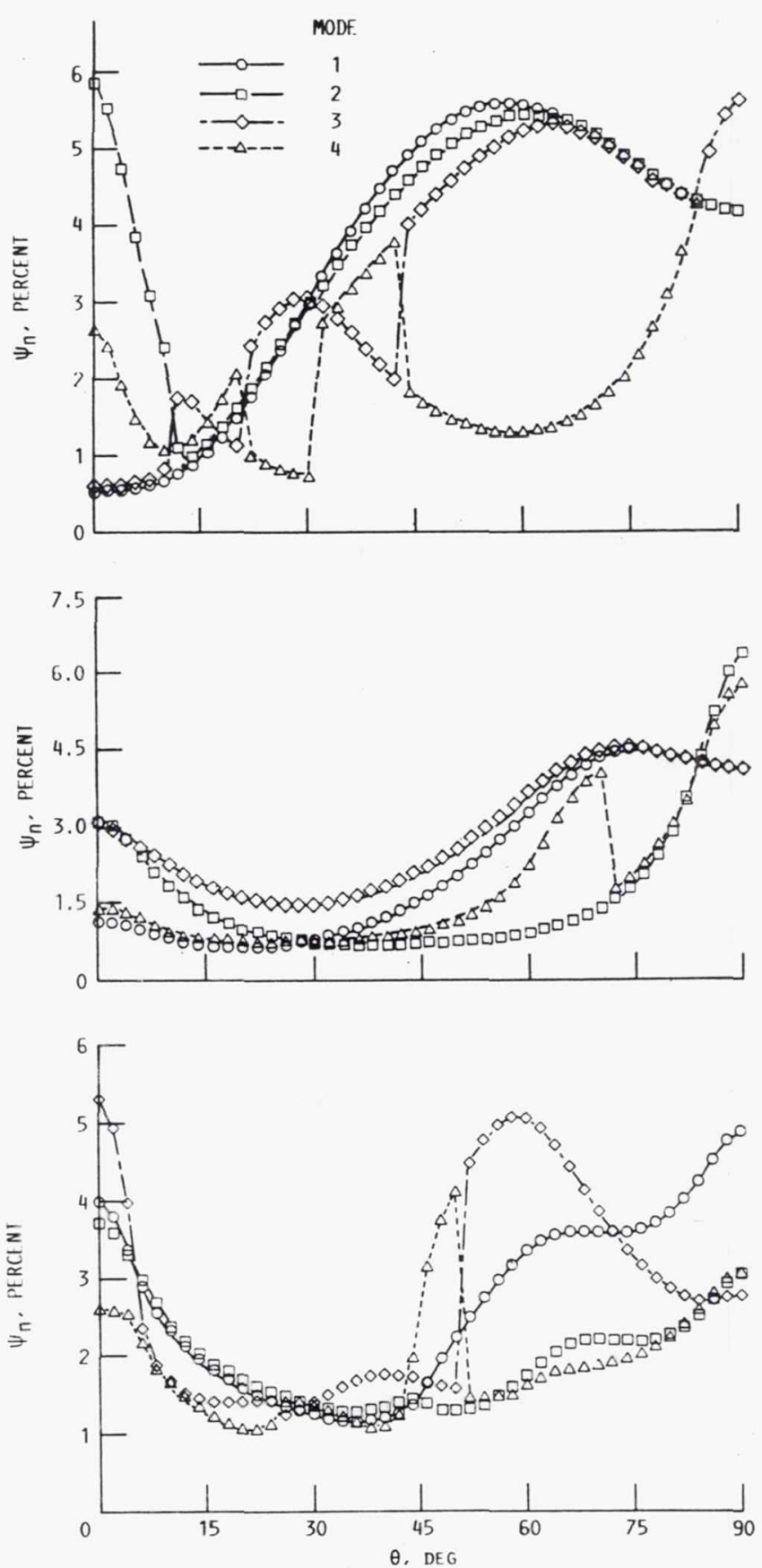

FIGURE 6. -EFFECT OF PLY ANGLE $\theta$ ON THE MODAL PROPERTIES OF VARIOUS SYMMETRIC ANGLE.PLY GRAPHITE/EPOXY COMPOSITE STRUCTURES. DIMENSIONS ARE IN INCHES. 


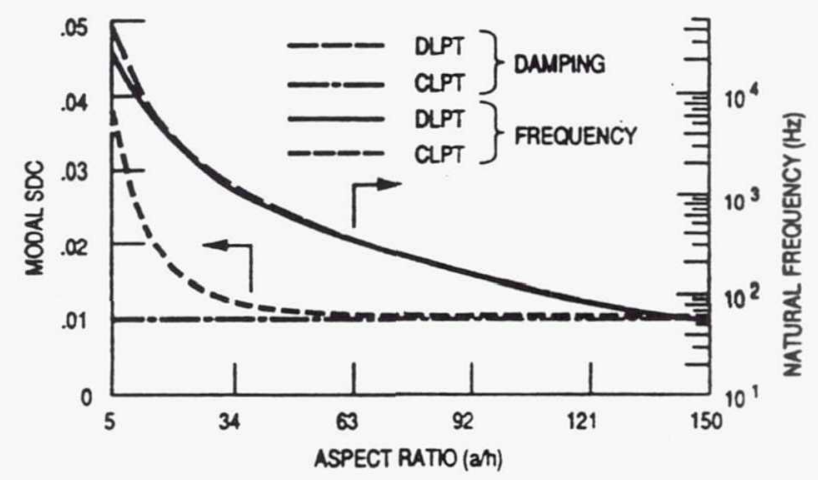

FIGURE 7. - EFFECT OF ASPECT RATIO ON THE FUNDAMENTAL MOOAL CHARACTERISTICS OF A $\left(Q_{4} / 9 Q_{4}\right)$ s HMSIEPOXY PLATE.
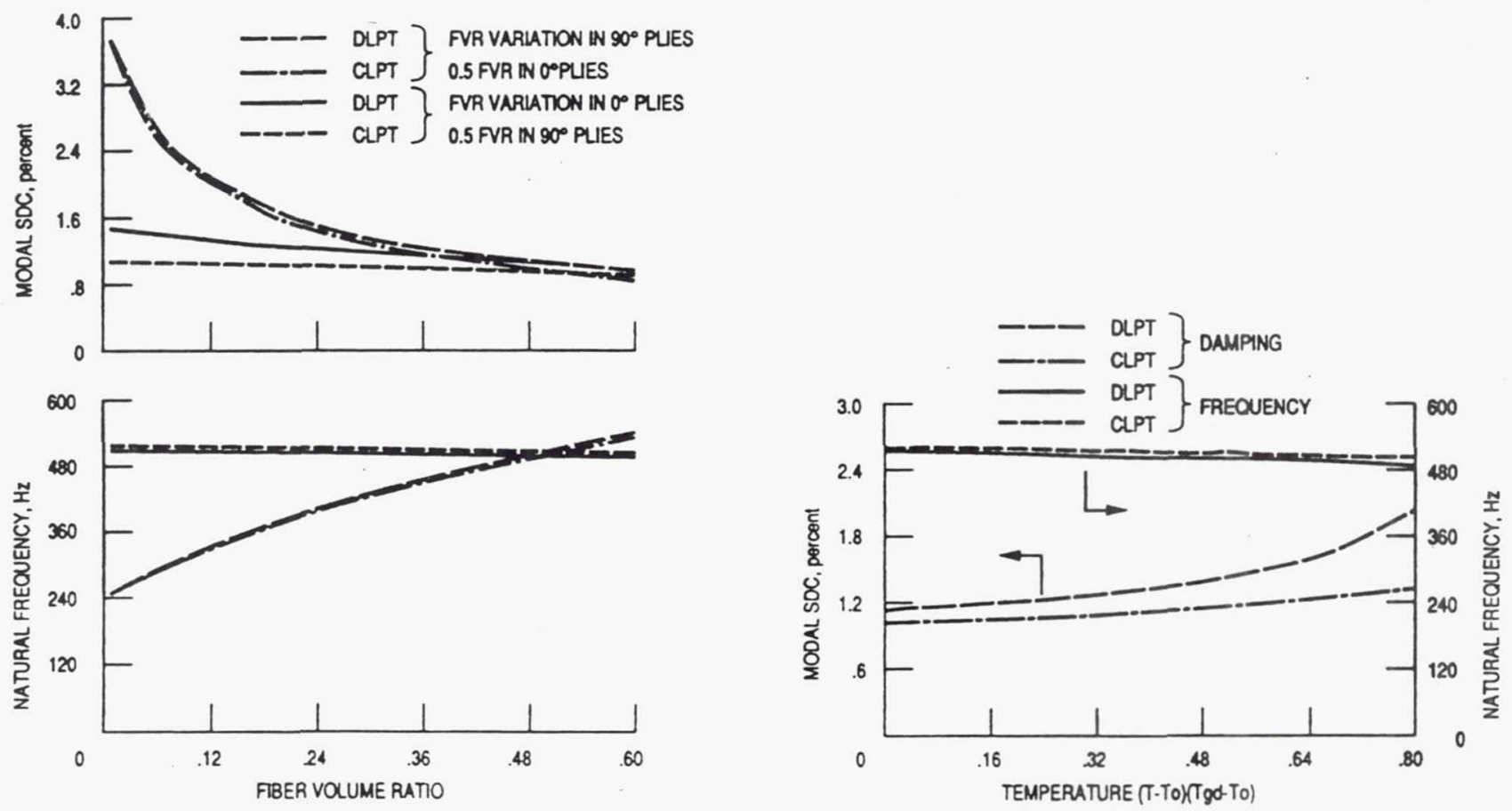

FIGURE 8. - EFFECT OF PVR ON THE FUNDAMENTAL MOOAL CHARACTERISTICS OF AN $\left(\mathrm{O}_{4} / 90_{4}\right)$ S HIM-S/EPOXY PLATE

FIGURE 9. -EFFECT OF TEMPERATURE ON THE FUNDAMENTAL MOOAL PROPERTES OF A $\left(0,490_{4}\right) s$ HM-SEEPOXY PLATE. 


\begin{tabular}{|c|c|c|c|c|}
\hline \multicolumn{5}{|c|}{ Report Documentation Page } \\
\hline $\begin{array}{l}\text { 1. Report No. } \\
\text { NASA TM -104346 }\end{array}$ & \multicolumn{2}{|c|}{ 2. Government Accession No. } & \multicolumn{2}{|c|}{ 3. Recipient's Catalog No. } \\
\hline \multirow{2}{*}{\multicolumn{3}{|c|}{$\begin{array}{l}\text { 4. Tithe and Subtitie } \\
\text { Integrated Mechanics for the Passive Damping of Polymer-Matrix } \\
\text { Composites and Composite Structures }\end{array}$}} & \multicolumn{2}{|l|}{ 5. Report Date } \\
\hline & & & \multicolumn{2}{|c|}{ 6. Performing Organization Code } \\
\hline \multirow[t]{2}{*}{$\begin{array}{l}\text { 7. Author(s) } \\
\text { D.A. Saravanos and C.C. }\end{array}$} & & & \multicolumn{2}{|c|}{$\begin{array}{l}\text { 8. Performing Organization Report No. } \\
\text { E- } 6120\end{array}$} \\
\hline & & & \multicolumn{2}{|c|}{$\begin{array}{l}\text { 10. Work Unit No. } \\
505-63-5 B\end{array}$} \\
\hline \multirow{2}{*}{\multicolumn{3}{|c|}{$\begin{array}{l}\text { 9. Performing Organization Name and Address } \\
\text { National Aeronautics and Space Administration } \\
\text { Lewis Research Center } \\
\text { Cleveland, Ohio } 44135-3191\end{array}$}} & \multicolumn{2}{|c|}{ 11. Contract or Grant No. } \\
\hline & & & \multirow{2}{*}{\multicolumn{2}{|c|}{$\begin{array}{l}\text { 13. Type of Report and Period Covered } \\
\text { Technical Memorandum }\end{array}$}} \\
\hline \multirow{2}{*}{\multicolumn{3}{|c|}{$\begin{array}{l}\text { 12. Sponsoring Agency Name and Address } \\
\text { National Aeronautics and Space Administration } \\
\text { Washington, D.C. } 20546-0001\end{array}$}} & & \\
\hline & & & \multicolumn{2}{|c|}{ 14. Sponsoring Agency Code } \\
\hline \multicolumn{5}{|c|}{$\begin{array}{l}\text { 15. Supplementary Notes } \\
\text { Prepared for the Mechanics and Mechanisms of Materials Damping Conference sponsored by the American Society for } \\
\text { Testing and Materials, Baltimore, Maryland, March 13-15, 1991. D.A. Saravanos, Case Western Reserve University, } \\
\text { Cleveland, Ohio } 44106 \text { and NASA Resident Research Associate at Lewis Research Center. C.C. Chamis, NASA Lewis } \\
\text { Research Center. Responsible person, D.A. Saravanos, (216) } 433-8466 \text {. }\end{array}$} \\
\hline \multicolumn{5}{|c|}{$\begin{array}{l}\text { 16. Abstract } \\
\text { Some recent developments on integrated damping mechanics for unidirectional composites, laminates, and composite } \\
\text { structures are reviewed. Simplified damping micromechanics relate the damping of on-axis and off-axis composites to } \\
\text { constituent properties, fiber volume ratio, fiber orientation, temperature, and moisture. Laminate and structural damping } \\
\text { mechanics for thin composites are summarized. Discrete layer damping mechanics for thick laminates, including the } \\
\text { effects of interlaminar shear damping, are developed and semi-analytical predictions of modal damping in thick simply- } \\
\text { supported specialty composite plates are presented. Applications demonstrate the advantages of the unified mechanics, } \\
\text { and illustrate the effect of fiber volume ratio, fiber orientation, structural geometry, and temperature on the damping. } \\
\text { Additional damping predictions for composite plates of various laminations, aspect ratios, fiber content, and temperature } \\
\text { illustrate the merits and ranges of applicability of each theory (thin or thick laminates). }\end{array}$} \\
\hline \multicolumn{2}{|c|}{$\begin{array}{l}\text { 17. Key Words (Suggested by Author(s)) } \\
\text { Composites; Damping; Unidirectional; Off-axis; } \\
\text { Laminates; Structures; Hygrothermal effects; Thin } \\
\text { composites; Thick composites; Interlaminar shear } \\
\text { damping }\end{array}$} & \multicolumn{3}{|c|}{$\begin{array}{l}\text { 18. Distribution Statement } \\
\text { Unclassified - Unlimited } \\
\text { Subject Category } 24\end{array}$} \\
\hline \multirow{2}{*}{$\begin{array}{r}\text { 19. Security Classit. (of the report) } \\
\text { Unclassified }\end{array}$} & \multirow{2}{*}{\multicolumn{2}{|c|}{$\begin{array}{r}\text { 20. Security Classif. (of this page) } \\
\text { Unclassified }\end{array}$}} & 21. No. of pages & 22. Price* \\
\hline & & & 26 & $\mathrm{~A} 03$ \\
\hline
\end{tabular}

